\title{
ABC of Alcohol
}

\section{ALCOHOL IN THE BODY}

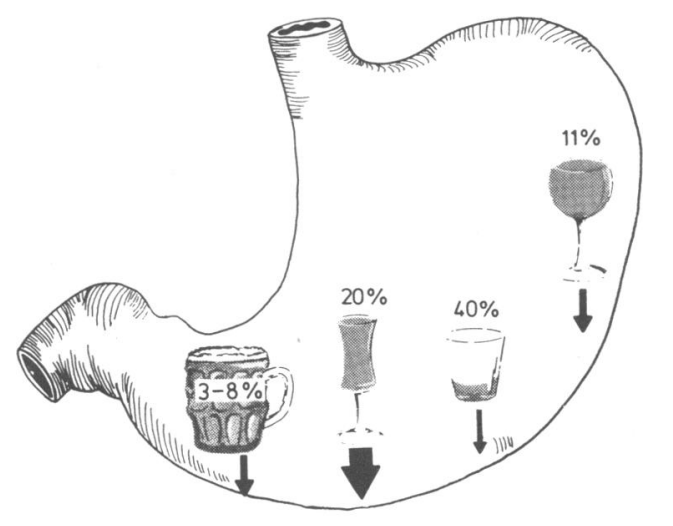

Many countries, including Britain, are suffering from an epidemic of alcoholism. Apart from the social harm, which is difficult to measure, over a hundred diseases have been attributed to alcohol abuse. It is important, therefore, that doctors know something about the handling of alcohol by the body, and some of its physiological effects.

Alcohol is absorbed from both stomach and small intestine, but is more rapidly absorbed from the latter. The rate of absorption is variable: it is most rapid when alcohol is taken on an empty stomach and when the concentration of alcohol in the drink is between $20 \%$ and $30 \%$. Thus sherry or vermouth (approximately $20 \%$ alcohol) raise blood concentrations more rapidly than beer $(3-8 \%)$, while spirits $(40 \%)$ delay gastric emptying and are absorbed more rapidly when diluted. Food, and particularly carbohydrates, retards absorption considerably: blood concentrations may not reach a quarter of those in the fasted state.

Alcohol is distributed throughout the body water, so most tissues-heart, brain; and muscles-are exposed to the same concentrations as in blood. Concentrations are higher in the liver, which receives blood via the portal vein from stomach and small bowel. Little alcohol enters fat because of its poor blood supply, so that women, with more subcutaneous fat, achieve higher blood concentrations than men, even when the amount of alcohol is adjusted for body weight.

Blood alcohol concentrations vary according to sex, size, and body build, previous exposure to alcohol, type of drink, whether it is taken with food, and whether drugs that affect gastric emptying are used. Initial blood concentrations are particularly high in patients who have had a partial gastrectomy.

Alcohol is eliminated predominantly by hepatic metabolism; only $2-5 \%$ is excreted unchanged in urine or breath. The amount customarily taken by heavy drinkers represents an enormous metabolic load, and the liver's capacity for dealing with such quantities is relatively limited, although the heavy drinker may adapt for a considerable time before his liver finally fails. Half a bottle of spirits, for example, is equivalent in molar terms to $500 \mathrm{~g}$ of aspirin or $1 \cdot 2 \mathrm{~kg}$ of tetracycline.

\section{Acetaldehyde}

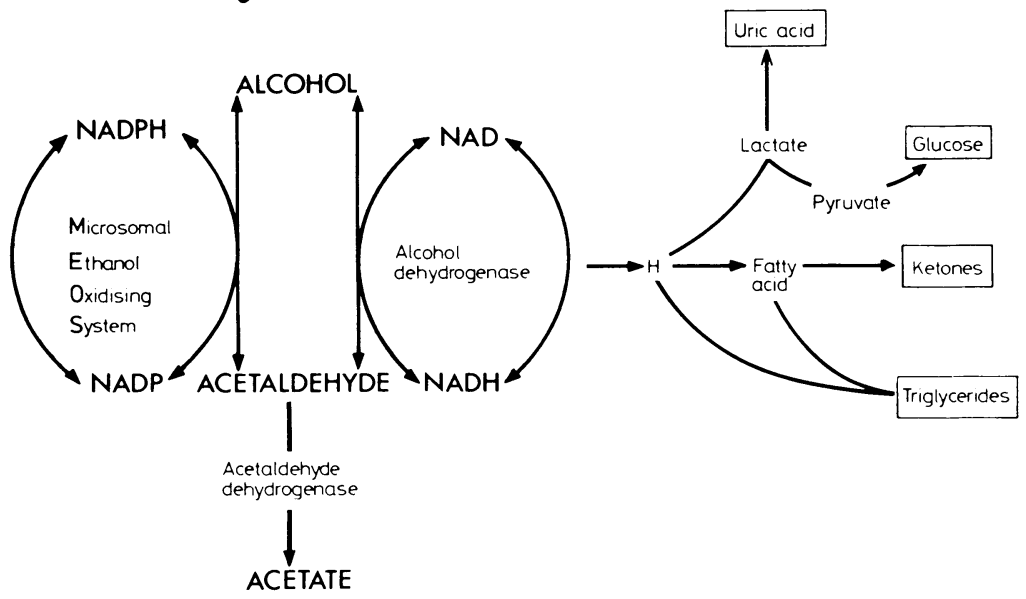

Most alcohol is metabolised to acetaldehyde, a highly reactive and toxic substance, which has been suspected for many years of being responsible for the physical damage caused by excessive alcohol consumption. Attempts to incriminate it have so far been unsuccessful. It is normally rapidly metabolised to acetate which is not toxic, and concentrations in most tissues are extremely low.

Several metabolic abnormalities result from the oxidation of excess alcohol, including overproduction of lactic and keto acids, retention of uric acid, hyperlipidaemia, and accumulation of fat in the liver. 


\section{Peak concentrations and rate of removal}

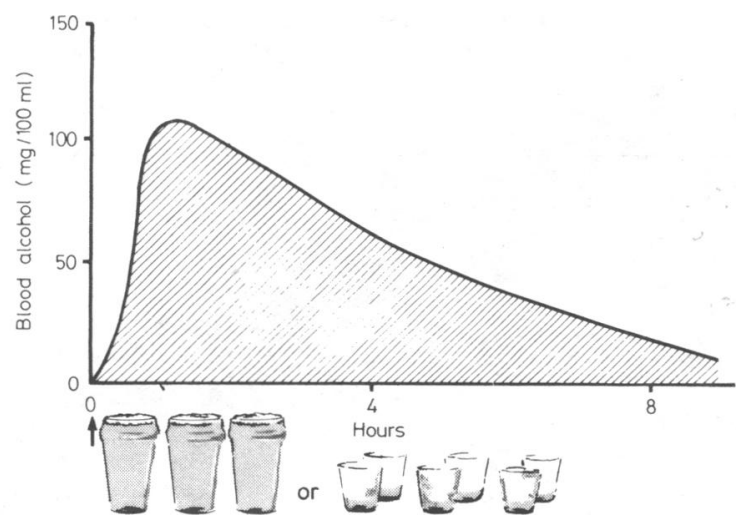

In health, alcohol is removed from the blood at a rate of about $15 \mathrm{mg} / 100 \mathrm{ml} / \mathrm{h}$, though there is a good deal of individual variation. Metabolism is accelerated in heavy drinkers unless they have liver damage, when it may fall to less than a quarter of normal. Detectable blood concentrations are present for over eight hours after three pints of beer or three double spirits in normal people; in patients with liver damage concentrations may remain high for over 24 hours.

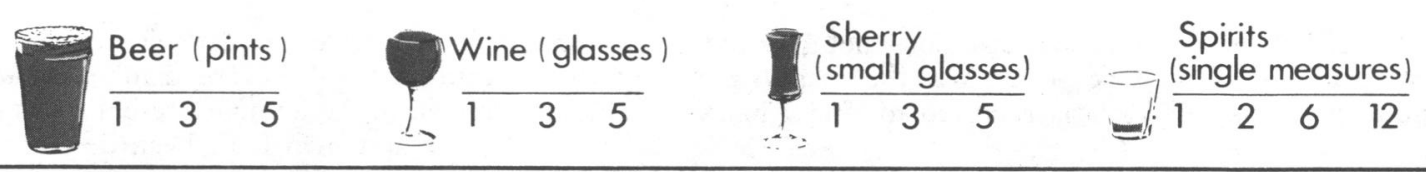

Alcohol content (g)

$20 \quad 60 \quad 100$

$10 \quad 30 \quad 50$

$1030 \quad 50$

$10 \quad 20 \quad 60 \quad 120$

Peak blood
concentration $(\mathrm{mg} / 100 \mathrm{ml})$

$30120 \quad 200$

$1550 \quad 100$

$20 \quad 60 \quad 120$

$20 \quad 40120 \quad 140$

\section{Effect on behaviour}

Alcohol has a euphoriant and disinhibiting effect, but even at low blood concentrations (around $30 \mathrm{mg} / 100 \mathrm{ml}$ ) the risk of accidental injury increases. In a simulated driving test, bus drivers with blood alcohol concentrations of $50 \mathrm{mg} / 100 \mathrm{ml}$ thought they could drive through obstacles that were too narrow for their vehicles. At $80 \mathrm{mg} / 100 \mathrm{ml}$ the risk of a road accident is more than doubled; at $160 \mathrm{mg} / 100 \mathrm{ml}$ it increases more than ten fold. Dysarthria and ataxia occur at concentrations of $160-200 \mathrm{mg} / 100 \mathrm{ml}$, when loss of consciousness may result. Concentrations above $400 \mathrm{mg} / 100 \mathrm{ml}$ are commonly fatal, especially if a sedative drug is also taken.

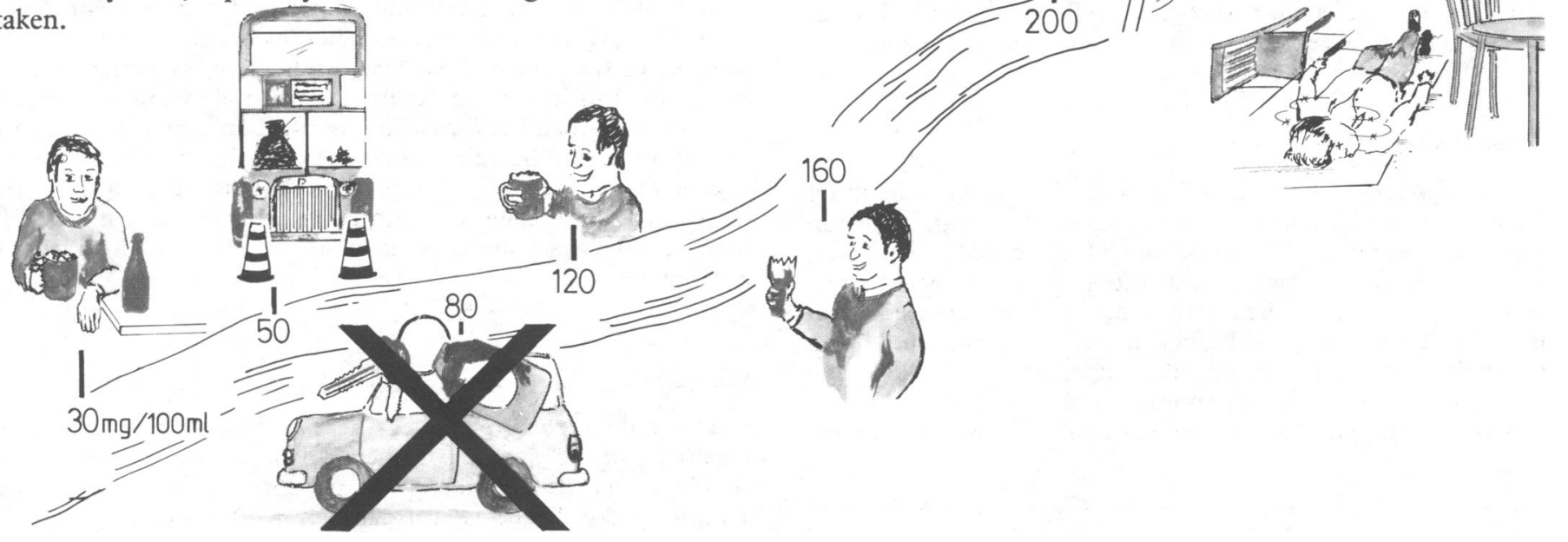

Dr J B Saunders, MB, MRCP, (now lecturer, Liver Unit, King's College Hospital, London) was formerly Sheldon clinical research fellow and Dr A Paton, MD, FRCP, consultant physician at Dudley Road Hospital, Birmingham.

The diagram of ethanol metabolism was adapted with permission from an article by Lieber CS. N Engl f Med 1978;298:356. 